rediscover lethal catatonia, and to develop criteria for distinguishing the idiopathic from the iatrogenic.

UMDS (Guy's Campus)

London Bridge, London SEI 9RT

JAMES LINDESAY

References

ALLAN, R. N. \& White, H. C. (1972) Side effects of parenteral longacting phenothiazines. British Medical Journal, i, 221.

ARnold, O. H. \& Stepan, H. (1952) Research on the problem of acute lethal catatonia. Weiner Zeitschrift Nervenheilk, 4, 235-237.

Burke, R. E. Fahn, S., Mayeux, R. Weinberg, H., Lours, K. \& WiLLNER, J. H. (1981) Neuroleptic malignant syndrome caused by dopamine-depleting drugs in a patient with Huntingdon disease. Neurology (NY), 31, 1022-1026.

Coons, D. J., Hillman, F. J. \& Marshall, R. W. (1982) Treatment of neuroleptic malignant with dantrolene sodium: a case report. American Journal of Psychiatry, 139, 944-945.

Pefle, R. \& Von Loetzen, I. S. (1973) Phenothiazine deaths: a critical review. American Journal of Psychiatry, 130, 306-309.

\section{Lithium and Piroxicam}

DEAR SIR,

Walbridge and Bazire (Journal, August 1985, 147, 206-207) report an important interaction between lithium carbonate and piroxicam. In their discussion they seem to overlook the possibility of lithium toxicity having been precipitated by piroxicam further compromising the patient's already deteriorated renal function (creatinine clearance rate 51 and $55 \mathrm{ml} / \mathrm{min}$ on two occasions).

The consequences of prostaglandin inhibition by a non-steroidal anti-inflammatory drug (NSAID), such as piroxicam, on renal function in healthy subjects is controversial (Gullner et al, 1980). It is clear, however, that renal function is most likely to be adversely affected by a NSAID if it is already compromised (Sellars \& Wilkinson, 1983). Prostaglandins become progressively more active with deteriorating renal failure (Calin, 1983). Renal prostaglandins (notably PGE2) are potent vasodilators of renal circulation. In experimental models of renal ischaemic stress, prostaglandin inhibition results in enhanced renal ischaemia since vasoconstriction is unopposed (Henrich, 1983).

The lithium toxicity may therefore have resulted from a sudden impairment of renal lithium excretion, mediated by prostaglandin inhibition by piroxicam.

\section{St Vincents Hospital \\ Elm Park \\ Dublin 4}

\section{References}

GüLLNER, H-G., et al. (1980) The role of the prostaglandin system in the regulation of renal function in normal women. American Journal of Medicine, 69, 718-724.

Sellars, L. \& Wilkinson, R. (1983) Adverse effects of antirheumatic drugs on the kidney. Adverse Drug Reactions 2, 51-56.

CalIN, A. (1983) In common clinical usage nonsteroidal antiinflammatory drugs infrequently produce adverse effects on the kidney. American Journal of Kidney Disease, 11, 485-488.

Henrich, W. L. (1983) Nephrotoxicity of nonsteroidal antiinflammatory agents. American Journal of Kidney Disease, 11, $478-484$.

\section{Schizophrenia with Good and Poor Outcome}

DEAR SIR,

The studies by Kolakowska and her colleagues (Journal, March, 1985, 146, 229-246 and April $1985,146,348-357$ ) illustrate the difficulty of obtaining longitudinal information from a crosssectional study. The authors attempted to relate CT scans, cognitive impairment and neurological soft signs to outcome of schizophrenia, but did not carry out these investigations on initial presentation; in most cases these examinations appear to have been done at or near the end of the outcome period. The authors found that enlarged ventricles and cognitive impairment were associated with unfavourable outcome, and went on to suggest that "organic deficit may contribute to an unfavourable outcome". This ignores the possibility that some of the abnormalities found may have been at least in part consequent upon poor outcome of factors associated with it rather than predictors of it.

The study is weakened by the high rate of attrition; only 59 out of 118 patients satisfying their inclusion criteria actually participated in the study. The authors are aware of this problem and state that "the sample cannot be considered as representative of the population from which it was drawn". This does not appear to have deterred them from making sweeping generalisations about possible sub-types of schizophrenia.

In our opinion, the demonstration that the ratio of plasma drug concentrations to drug dose does not differ between the various outcome or response groups is not proof enough to eliminate all likelihood of pharmacological tolerance in the patients receiving fluphenazine or fluphenthixol who responded unsatisfactorily to these drugs. Information about the tubero-infundibular-dopaminergic axis obtained from plasma prolactin levels cannot be extrapolated to other regions of the brain such as the limbic or cortical areas (Thorner \& Evans, 1984). It also leaves unanswered the question of plasma levels of psychoactive metabolites, and also the possibility of pharmacodynamic tolerance. 